\title{
Bilateral Malleus Ankylosis: a Case Report
}

\section{Tatari MM*, Abouelfadl M, Abada LR, Rouadi S, Roubal M and Mahtar M}

Department of Otorhinolaryngology, Face and Neck Surgery, 20 August 1953 Hospital in Casablanca, Morocco

*Corresponding author: Tatari MM, Resident, Department of Otorhinolaryngology, Face and Neck Surgery, 20 August 1953 Hospital in Casablanca, 25 Ahmed Skiredj Street, Quartier Souriyyine, Tangier, Morocco, Tel: 0663001027, E-mail: tatari_moutaa@hotmail.com

Citation: Tatari MM, Abouelfadl M, Abada LR, Rouadi S, Roubal M, et al. (2016) Bilateral Malleus Ankylosis: a Case Report. J Case Rep Stud 4(3): 307. doi: 10.15744/2348-9820.4.307

Received Date: April 11, 2016 Accepted Date: June 20, 2016 Published Date: June 22, 2016

\begin{abstract}
Malleus ankylosis known as House syndrome is very rare. It represents $38.1 \%$ of congenital malformation of the middle ear [1] if stapes ankylosis is associated.

We have report a case of bilateral Malleus ankylosis without stapes ankylosis. That's make our study interesting because it's very rare and it's rarely described in the literature.

Clinically, it's reveal by a congenital conductive hearing loss bilateral isolated, without vertigo or tinnitus, and normal otoscopy exam. Normal ear drums. Ct scan is the main exam for visualization of ossicular chain and research others anomalies.

The diagnosis is confirmed during surgery.

The surgery consists of an ossiculoplasty, by section of the Malleus neck with interposition with Incus. Stapes has normal mobility without ankylosis.

We got good result by gain of $20 \mathrm{db}$ in the principal frequency after 3 mounts. Our patient is satisfied. The other side will be programmed one year later.
\end{abstract}

Keywords: Bilateral Ankylosis; Malleus; House Syndrome; Otosclerosis; Interposition Malleus; Incus

\section{Introduction}

HOUSE syndrome is a rare clinicopathological entity described initially by Goodhill [2] in 1966.

The congenital origin seems to be the most commonly accepted, but may also be found on healthy ear malformation pathology.

It is mainly found when working on a suspicious ear otosclerosis and represents a significant cause of revision surgery in this disease. Diagnostic confirmation of House Syndrome is operative. The aim of our study was to analyze the findings of middle ear exploration and the frequency of ossicular and footplate area anomalies in patients with suspected otosclerosis.

\section{Case Report}

It's about a young woman, 30 years old, with no family history of deafness, consulting for bilateral hearing loss from predominantly left worsening the last two years without other associated signs as vertigo or tinnitus. Otoscopic exam find normal ear drums. The rest of the ENT examination was unremarkable.

The audiogram includes conductive hearing loss of $65 \mathrm{~dB}$ in the left ear and $50 \mathrm{~dB}$ in the right one.

Temporal bone CT scan left and right reveal fixation of the Malleus in tegmen tympani by a bone bridge (Figure 1 and 2 ).

The surgery consists of a middle ear exploration. All of the three chain bone was explored. Stapes footplate was normal and no otosclerosis was found. The head of the malleus may be fixed to the bony walls of the epitympanic recess. An ossiculoplasty was done, by section of the Malleus neck with interposition with Incus.

Audiometry after 3 months shows a good result especially for 1000 and $2000 \mathrm{~Hz}$ with a gain of $20 \mathrm{db}$. The patient is satisfied.

The other surgery will be programmed one year later by the same procedure. 


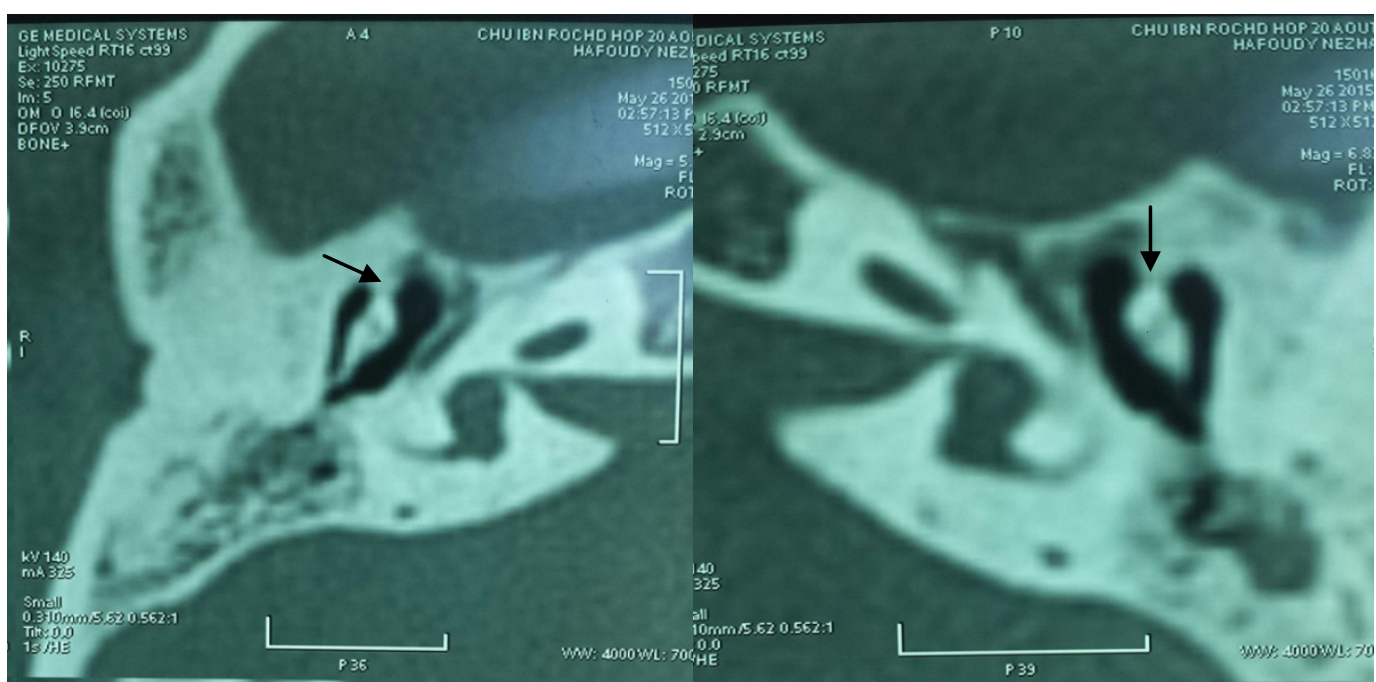

Figure 1: Temporal bone CT scan (axial images) right and left showing the bone bridge between the malleus head and tegmen tympani (Dark arrows)

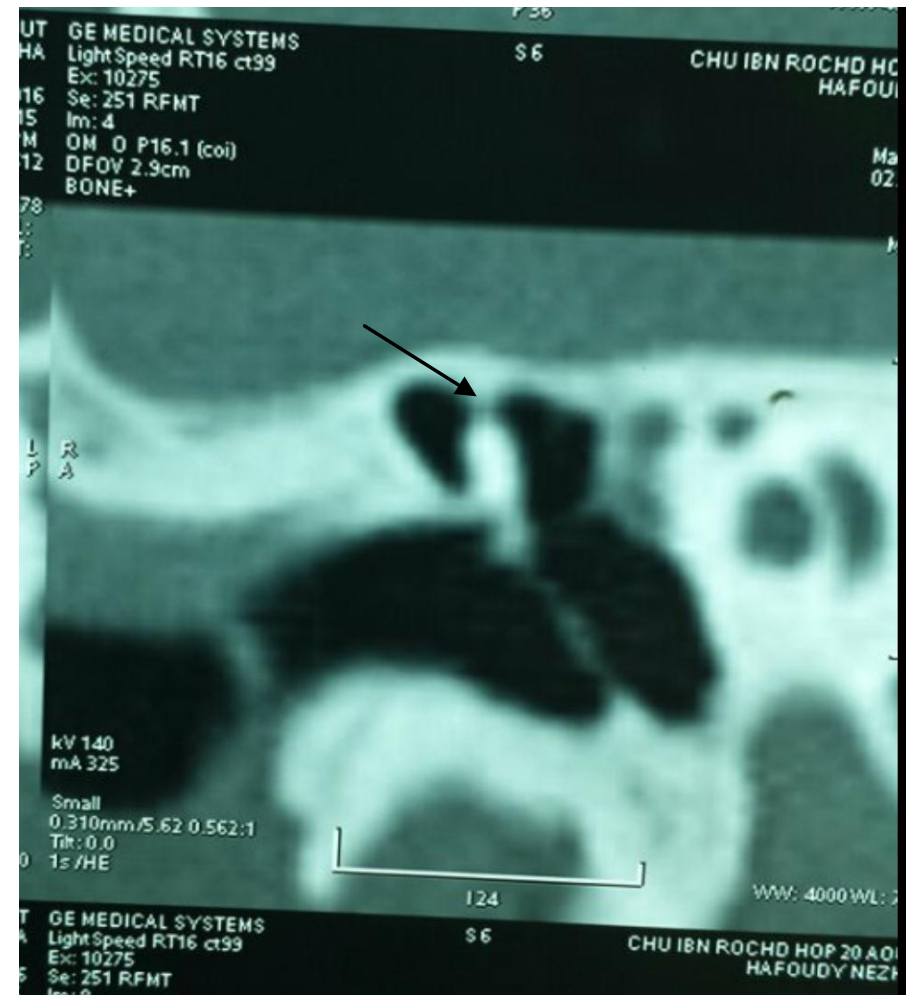

Figure 2: Temporal bone CT scan (coronal image) showing the bone bridge between the malleus head and tegmen tympani (Dark arrows)

\section{Discussion}

Congenital anomalies of the middle ear can be classified into major, when associated with a involvement of tympanic membrane and external ear, or minor, when there is an exclusive involvement of the middle ear $[1,3,4]$.

In 1993, Teunissen and Cremers [1,4] created a classification of minor malformations, based on the surgical approach, dividing them into four main groups: isolated stapes ankylosis, stapes ankylosis associated with other ossicular malformations, deformity of the ossicular chain with mobile stapes footplate, and severe aplasia or dysplasia of oval or round windows (Table 1).

House syndrome or Fixed malleus head syndrome corresponds to a primitive attachment, often bilateral, of the Malleus head in epitympanum by an anterior or upper synostose rarely medial [5].

Its frequency is low, reaching $1 \%$ of interventions on the middle ear according to some series [6].

It differs secondary ossifying process of the middle ear, whether inflammatory or traumatic. 


\begin{tabular}{|c|c|c|}
\hline Class & Malformations & $\%$ \\
\hline 1 & Ankylosis or isolated congenital fixation of the stapes & $30,6 \%$ \\
\hline 2 & $\begin{array}{l}\text { Stapes ankylosis associated with other malformations of the Ossicular chain: } \\
\text { - Deformities of the incus and/ or malleus, or aplasia of } \\
\text { the long apophysis of the incus. } \\
\text { - Bone fixation of the malleus and/or incus }\end{array}$ & $38,1 \%$ \\
\hline 3 & $\begin{array}{l}\text { Congenital anomalies of the ossicular chain with mobile stapes Footplate: } \\
\text { - Disruption of the ossicular chain } \\
\text { - Epitympanic fixation } \\
\text { - Tympanic fixation }\end{array}$ & $21,6 \%$ \\
\hline 4 & $\begin{array}{c}\text { Congenital aplasia or severe dysplasia of the oval and round windows: } \\
\text { - Aplasia } \\
\text { - Dysplasia } \\
\text { • Prolapse of facial nerve } \\
\text { persistence stapedial artery }\end{array}$ & $9,7 \%$ \\
\hline
\end{tabular}

Table 1: Classification of minor congenital malformations according to Teunissen and Cremers

Congenital etiology seems most likely and based on several findings:

- Absence of otologic history

- Healthy ears without inflammatory changes, with a normally developed pneumatic system

- The frequency of associations with other birth defects

- The existence of bilateral forms

Clinically, House syndrome manifested by progressive unilateral or bilateral deafness, with normal eardrum, and indifferently affects both sexes no age predilection.

Audiometry shows a moderate conductive hearing loss, not exceeding $30 \mathrm{~dB}$.

CT scan is the method of choice, since it allows for a correct visualization of bony structures. It enables the positive diagnosis of fixing Malleus head on the attical wall, and look at the same time signs associated with otosclerosis. However, exploratory tympanotomy is the method that most reliably establishes the definitive diagnosis [5].

The classification proposed by Charachon et al. [5] takes into account the description of ossicular anomalies and their embryological origin (Table 2). Then, our case report is about class II, because we have only a fixation of malleus head without sign of otosclerosis proved during surgery. Class II is the most common case according to Charachon's classification.

\begin{tabular}{|c|c|}
\hline CLASS 0 & $\begin{array}{r}\text { Normal ossicular chain, almost normal tympanic membrane but small atretic } \\
\text { plate around malleus handle }\end{array}$ \\
\hline CLASS 1 & $\begin{array}{r}\text { Fixation of the malleus head } \\
\text { CLASS 2 }\end{array}$ \\
\hline CLASS 3 & $\begin{array}{r}\text { Lormal ossicular chain but fixation of the footplate } \\
\text { 2a: with abnormality of the facial nerve } \\
\text { 2b:without abnormality of the facial nerve }\end{array}$ \\
\hline CLASS 4 & Sever malformation of all the ossicular chain. \\
\hline
\end{tabular}

Otosclerosis is a disease of bony labyrinth. Structural changes in the labyrinth often cause ossicular fixation, and thus conductive hearing loss. Otosclerosis (OS) is the most common etiology of conductive hearing loss in 15-50 years old patients with intact tympanic membrane [7]. This is a disorder of bone which nearly exclusively involves the otic capsule [8].

The disease presents clinically in about $1 \%$ of Caucasians, and is transmitted as an autosomal dominant trait with incomplete penetrance. In practice otosclerosis is seen more often in women than men by the ratio of approximately 2:1 [9]. The prevalence of OS varies with race, and in whites the disease is found in $7.3 \%$ and $10.3 \%$ of temporal bones for men and women respectively. The stapes appears fixed in only $12.3 \%$ of patients with histopathologic evidence of otosclerosis [10].

Patients notice a slowly progressive hearing loss in one or both ears. With bilateral involvement one ear is usually affected more than the other. Tinnitus may be present, but vestibular dysfunction due to OS is rare. The differential diagnosis of conductive hearing loss with intact tympanic membrane includes: middle ear anomalies, ossicular chain disruptions, generalized disorders of bone metabolism such as Paget disorder, osteogenesis imperfect and so on.

Besides fixations of stapes footplate, the head of the malleus may be fixed to the bony walls of the epitympanic recess (malleus head fixation): this may occur idiopathically, postoperatively or in the setting of tympanosclerosis [11-13]. 
As we searched in English literature, we could not find any similar study in which the researchers investigated the frequency of ossicular and footplate area anomalies in patients with suspected OS. Many of the papers are limited case reports, and it seems that the frequency of ossicular anomalies is better to be evaluated and compared in different countries.

Two surgical approaches are possible to restore the mobility of ossicular chain: The simplest is the classic incus transposition with the Malleus section neck, the more physiological directly suppresses atticale synostosis respecting the ossicular continuity in case of isolated binding, as is the case in our study (Class I), or by making a gesture footplate if ankylosis stapedovestibular associated (Class III).

\section{Conclusion}

Isolated hearing loss, unilateral or bilateral, needs a middle ear exploration. It can be an otosclerosis only, or otosclerosis associated to malformations of middle ear area (ossiclar chain anomalies, fixation of head of malleus...). The diagnostic is confirmed during surgery. The most common case is the class II of Charachon. We could not find any similar study in which the researchers investigated the frequency of ossicular and footplate area anomalies in patients with suspected OS. Many of the papers are limited case reports, and it seems that the frequency of ossicular anomalies is better to be evaluated and compared in different countries.

\section{References}

1. Teunissen EB, Cremers WR (1993) Classification of middle ear anomalies. Report on 144 ears. Ann Otol Rhinol Laryngol 102: 606-12.

2. Goodhill V (1960) Pseudo-Otosclerosis. Laryngoscope 70: 722-57.

3. Swartz JD, Faerber EN (1985) Congenital malformations of the external and middle ear: high-resolution CT findings of surgical import. AJR Am J Roentgenol 144: 501-6.

4. Cremers CW, Teunissen E (1991) The impact of a syndromal diagnosis on surgery for congenital minor ear anomalies. Int J Pediatr Otorhinolaryngol 22: 59-74.

5. Esteves SD, Silva AP, Coutinho MB, Abrunhosa JM, Almeida e Sousa C (2014) Congenital defects of the middle ear--uncommon cause of pediatric hearing loss. Braz J Otorhinolaryngol 80: 251-6.

6. House HP (1963) Early and late complications of stapes surgery. Arch Otolaryngol 78: 606-13.

7. De Souza C, Goycoolea MV, Sperling NM (2014) Otosclerosis: diagnosis, evaluation, pathology, surgical techniques, and outcomes. Plural Publishing, USA.

8. Bales P (1997) Scott-Brown's Otolaryngology ( $5^{\text {th }}$ Edn) Published by London Boston: Butterworths, London.

9. Baily BJ (2001) Head and Neck Surgery: Otolaryngology ( $3^{\text {rd }}$ Edn) Lippincott Williams \& Wilkins Publisher, USA.

10. Flint PW, Haughey BH, Lund VJ, Niparko JK, Richardson MA, et al. (2010) Cummings Otolaryngology - Head and Neck Surgery (5 ${ }^{\text {th }}$ Edn) Philadelphia: Mosby Elsevier, USA.

11. Probst R, Greves G, Iro H (2006) Otorhinolaryngology (2 $2^{\text {nd }}$ Edn) Germany: thieme, Germany.

12. Karhuketo TS, Ilomäki JH, Dastidar PS, Laasonen EM, Puhakka HJ (2001) Comparison of CT and fiberoptic video-endoscopy findings in congenital dysplasia of the external and middle ear. Eur Arch Otorhinolaryngol 258: 345-8.

13. Elden LM, Zur KB (2013) Congenital Malformation of the head and neck. Springer Book, London.

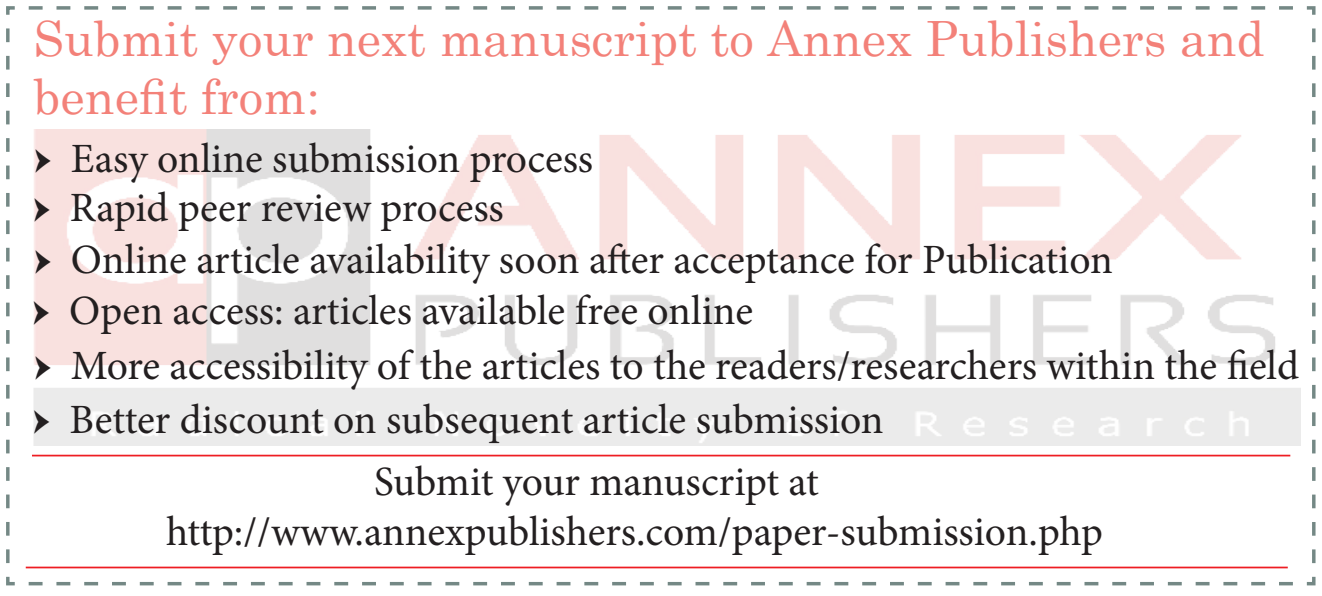

